Note

\section{Ultraviolet Difference Spectra of Chymosin at Acidic pH}

\author{
Yoshihiro Kanamaru,* Ryoya NiKI \\ and Shunrokuro ARIMA \\ Institute for Dairy Science. Faculty of \\ Agriculture, Hokkaido University. \\ Kita-ku, Sapporo 060, Japan
}

Received August 10, 1979
Chymosin (EC 3.4.23.4) is the major proteolytic enzyme in the stomach of the preruminant calf. Recently its primary structure was established and found to be very similar to that of pepsin. "In 1959, it was reported that spectral shifts of pepsin solution were observed by acidification from $\mathrm{pH}$ 4.6 to 1.0 , but these spectral changes seemed to have no direct relation to the enzyme activity. ${ }^{2)}$ We measured ultraviolet spectra of chymosin solution at acidic $\mathrm{pH}$ in order to know if similar spectral changes are also observed by acidification. Chymosin was prepared as described by Yoshino et al. ${ }^{3)}$ Freeze-dried chymosin was dissolved in $0.02 \mathrm{M}$ sodium acetate buffer ( $\mathrm{pH} 5.5$ ) and dialyzed at $4 \mathrm{C}$ for at least $48 \mathrm{hr}$ against the same buffer. The protein solution was then centrifuged for $30 \mathrm{~min}$ at $20,000 \mathrm{rpm}$ in order to remove any insoluble materials. Ultraviolet difference spectra were measured with a Hitachi recording spectrophotometer (model EPS-3T) at room temperature. Quartz cells with 1-cm light paths were used for measurement. A set of solutions for series of spectrophotometric scans consisted of a reference solution $(\mathrm{pH} \mathrm{5.5)}$ and the sample solutions with different $\mathrm{pHs}$ but with the same concentration of the protein as that of the reference solution. These sample solutions were prepared by adding appropriate quantities of acid $(6 \mathrm{~N} \mathrm{HCl})$ to give desired $\mathrm{pH}$. $\mathrm{pH}$ measurements were carried out both before and after the spectrophotometric measurements at room temperature.

When chymosin solutions at lower pHs were measured with a $\mathrm{pH} 5.5$ solution as a reference, shift in the ultraviolet absorption spectra was observed. Spectral changes occurred in the 270 to $300 \mathrm{~nm}$ wavelength regions having maxima at 287.5 and $295 \mathrm{~nm}$ (Fig. 1). The $295 \mathrm{~nm}$ peak can be attributed solely to the spectral changes of tryptophan residues, while the $287.5 \mathrm{~nm}$ peak may reflect the spectral changes of both tryptophan and tyrosyl residues. Chymosin contains, in addition to four tryptophan groups,

* Present address: Department of Poultry and Animal Sciences, Faculty of Agriculture, Gifu University, Kakamigahara-shi, Gifu 504, Japan.

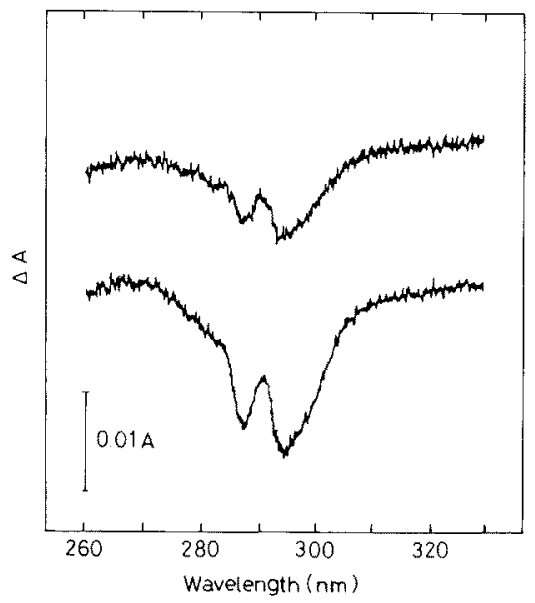

Fig. 1. Difference Spectra of Acidic Chymosin Solutions.

pHs of the sample solutions were 3.16 (upper) and 1.89 (lower). Protein concentration was $0.5 \mathrm{mg} / \mathrm{ml}$. It was determined spectrophotometrically using the following extinction coefficient; $E_{278}^{1 \%}=14.3^{41}$ ' $A$ ' means absorbance.

nineteen tyrosyl groups in a total of 323 amino acid residues. "But both the findings that changes in $\Delta \varepsilon_{287.5}$ are proportional to those in $295 \mathrm{~nm}$ peak and that only tryptophan can give difference spectral maxima at these two wavelengths ${ }^{5}$ suggest that the contribution of tyrosyl absorption to these spectral changes can be neglected. Therefore, it may be concluded that the spectral changes observed are due to some alteration of the environment of the tryptophan residue(s) in the chymosin molecule as the protein is brought from $\mathrm{pH} 5.5$ to lower pHs. The magnitude of both peaks in Fig. I was found to depend upon pH. As illustrated in Fig. 2, where the molar difference absorption coefficient at $295 \mathrm{~nm}$ is plotted against $\mathrm{pH}$, a steady decrease in absorbancy was obtained between $\mathrm{pH} 4.5$ and 2 and plateau was reached at $\mathrm{pHs}$ near one. No major change in the value of $\Delta \varepsilon_{\lambda}$ was observed with change in ionic strength over the range $0.02 \sim 0.5$. While the spectral shifts observed at acid $\mathrm{pH}$ appear to be the consequence of a structural change in the molecule, the manner in which this change alters the environment of the tryptophan group is not immediately obvious. The possibility of the unfolding of the protein molecule can be ruled out as the main cause for the observed changes on acidification, since chymosin is very stable enzyme at acid $\mathrm{pH}$ as the case of pepsin. Indeed, the magnitude of the maximum value of $\Delta \varepsilon_{295}(-1100)$ is too small to anticipate for the unfolding of the peptide. Thus the spectral changes observed should not be the result of "denaturation blue shift." The sigmoidal curve obtained in Fig. 2 suggests that one or more ionizable groups should participate in the present spectral changes of chymosin. The degree of $\mathrm{pH}$ 


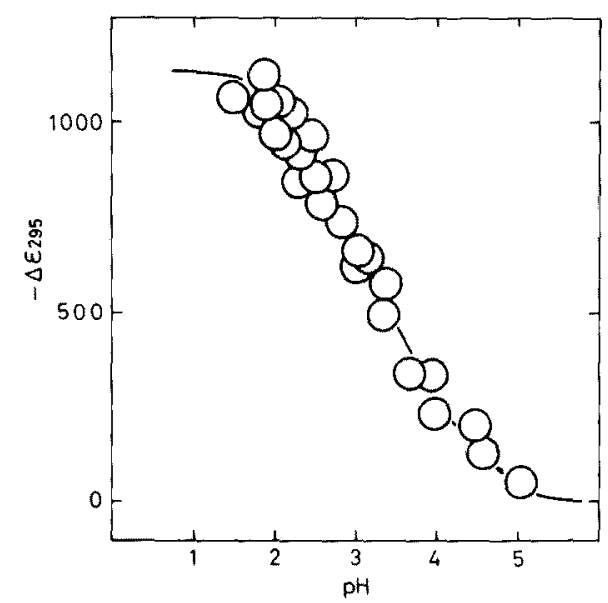

FIG. 2, pH Dependence of $\Delta \varepsilon_{295}$ of Chymosin.

The molecular weight used for calculation of $\Delta \varepsilon$ is 35,652 . $^{11}$

dependence of $\Delta \varepsilon_{\lambda}$ value is the same as that of dissociation of the ionizable groups. We analyzed the data given in Fig. 2 according to Kronman ef al.," where an equilibrium in the state of tryptophan group between reference $\mathrm{pH}(5.5)$ and lower $\mathrm{pH}$ was assumed. A linear relationship with the slope of -0.7 was obtained between logarithm of the equilibrium constant and $\mathrm{pH}$. This result suggests that only one ionizable group is enough to be concerned and that the protonation reaction of the ionizable group induces the spectral changes of the tryptophan group. This ionizable group is supposed to be carboxyl, because the $p K_{\mathrm{app}}$ value is estimated to be 3.3 . One of the possible explanation of the present spectral changes is that the carboxyl group with $\mathrm{p} K$ value of 3.3 interact strongly with the tryptophan residue and that the charge effect takes place through the solvent at small distances between the charged group and the indole chromophore. Similar difference spectra due to the charge effect of the carboxyl groups in the vicinity of the tryptophan residues have been observed for lysozyme ${ }^{71}$ and $\alpha$ lactalbumin. ${ }^{6}$ On the other hand, it seems also important to note that chymosin apparently exists as a monomer only at low $\mathrm{pH}$ and as a dimer at slightly acid $\mathrm{pH}^{8}{ }^{8}$ If indeed an association reaction takes place in the $\mathrm{pH}$ region of the present investigation, it may induce the alteration of the environment of the tryptophan group.

\section{REFERENCES}

1) B. Foltmann, V. R. Pedersen, H. Jacobsen, D. Kauffman and G. Wybrandt, Proc. Natl. Acad. Sci. USA, 74, 2321 (1977).

2) O. O. Blumenfeld and G. E. Perlmann, J. Gen. Physiol., 42, 563 (1959).

3) U. Yoshino, N. Nakatani, Y. Tokoro and K. Yamauchi, Nippon Nôgeikagaku Kaishi, 40, 52 (1966).

4) B. Foltmann, Compt. Rend. Trav. Lab. Carlsberg, 35 , 143 (1966).

5) S. Yanari and F. A. Bovey, J. Biol. Chem., 235, 2818 (1960).

6) M. J. Kronman, J. Jeroszko and G. W. Sage, Biochim. Biophys. Acta, 285, 145 (1972).

7) J. W. Donovan, M. Laskowski, Jr. and H. A. Scheraga, J. Am. Chem. Soc., 83, 2686 (1961).

8) G. C. Cheeseman, J. Dairy Res., 36, 299 (1969). 